\title{
ORDENAMENTO TERRITORIAL E A RESOLUÇÃO DE CONFLITOS NO TERRITÓRIO A PARTIR DA POLÍTICA PÚBLICA DE MEDIAÇÃO
}

\author{
Gissele B. Leal Bertagnolli* \\ Rosane Bernardete Brochier Kist**
}

\begin{abstract}
Resumo
Neste artigo, realiza-se uma análise sobre as reflexões e os elementos conceituais relacionados com a temática do ordenamento Territorial e da resolução de conflitos através da mediação. No que se refere ao ordenamento territorial, utilizam-se como base algumas obras dos autores João Ferrão e Ursula Caser que se constituem como referências para a compreensão do tema a partir de uma perspectiva interdisciplinar. Procurou-se evidenciar a necessidade da implantação não só do planejamento mas também de métodos que contribuam para a resolução de conflitos, como conciliações e mediações. Nesse contexto, realizam-se algumas reflexões relacionadas com o ordenamento territorial, o desenvolvimento regional, a conciliação, a mediação e as políticas públicas. A metodologia baseia-se em uma pesquisa bibliográfica. As principais conclusões apontam que o Brasil, sendo um País de grandes diversidades e, também, sob o aspecto social, é um complexo de diferentes grupos humanos, com territorialidades próprias, marcado por diferentes interesses que, por muitas vezes, têm a necessidade de conciliar-se entre si. Além disso, verificou-se que, após a conclusão dos processos de mediação, acontece algo mais do que simplesmente uma solução para o conflito, pois na realidade e em alguns casos também significa a retomada de relações que até então estavam estremecidas devido ao impasse judicial. No aspecto da territorizalização, a mediação se constitui em um processo de desenvolvimento social, na medida em que busca auxiliar a população local frente a situações que provocam desgastes, sejam emocionais, sociais ou financeiros.
\end{abstract}

Palavras-chave: Políticas Públicas. Território. Conciliação. Mediação.

\footnotetext{
* Bacharel em Direito pelo Centro Universitário Franciscano (UNIFRA), Santa Maria/RS; Pós-Graduada em Mediação de Conflitos e Direito de Família pela Faculdade Palotina (FAPAS), Santa Maria/RS; Mestre em Desenvolvimento Regional, pela Universidade de Santa Cruz do Sul (UNISC), Santa Cruz do Sul/RS. E-mail: gissele1106@gmail.com

** Assistente Social (UNISC); Mestre e Doutora em Serviço Social (PUC-RS); Pós-Doutora em Desenvolvimento Regional (PPGDR/UNISC). Docente do Programa de Pós-Graduação em Desenvolvimento Regional da Universidade de Santa Cruz do Sul (PPGDR/UNISC) no período de 2012 a 2016. Integrante do GEPEUR-CNPq e do OBSERVA-DR.E-mail: rosanekist2009@hotmail.com
} 


\section{Introdução}

No que se refere ao ordenamento territorial, é importante ressaltar que ele está relacionado com o ato de ordenar os múltiplos usos do território, impostos pelas atividades humanas de produção e de reprodução, abrangendo as atividades, assim como suas formas de ocupação de seus recursos naturais existentes no tempo e no espaço. Para que ordenar? É na definição dos propósitos do ordenamento que a ideologia do Estado primeiramente se apresenta, ou seja, no discurso. Algumas questões estão presentes na maioria das leis sobre ordenamento territorial, entre elas, o desenvolvimento socioeconômico equilibrado das regiões, a melhoria da qualidade de vida, entre outros aspectos.

Entretanto, há muitos desafios que necessitam ser superados para pensar uma política nacional de ordenamento do território. Nesse contexto, Ferrão (2011) entende que a política de ordenamento do território é essencial para promover lugares, regiões, países e espaços transnacionais mais atrativos, sustentáveis, desenvolvidos, justos e democráticos. $\mathrm{Na}$ acepção atual do ordenamento territorial, considera-se como possuindo caráter interdisciplinar, isto é, prospectivo, sendo o ordenamento voltado à utilização ótima do espaço (FERRÃO, 2011).

Quando se fala em territorialidade da política pública, é importante reconhecer e observar o território como uma dimensão básica para a caracterização da população que ali vive, bem como conhecer suas problemáticas para avaliar as repercussões dos serviços prestados a essa população (SORRENTINO, 2005). Nesse sentido, a mediação e a conciliação, apontada como um método de resolução de conflitos que se desenvolve de forma pacífica e consensual, buscando a preservação do relacionamento, deve considerar as características daquele universo onde está inserida, pois: “[...] o território é o chão e mais a população, isto é, uma identidade, o fato e o sentimento de pertencente àquilo que nos pertence" (SANTOS, 1994, p. 96). 
Segundo Etges (2005, p. 13), um território “[...] traz a marca de gerações. É resultante dos embates políticos, econômicos e sociais do nível tecnológico que os seus habitantes alcançaram. É resultante do tipo de organização social ali criada, algo que está continuamente em processo". Assim, entende-se que a territorialidade é fator que merece ser considerado quando se busca um consenso por meio de mediação; afinal, em caso contrário, algumas barreiras podem surgir, sejam por divergências de princípios, de cultura, ou por outros fatores ligados à identidade territorial dos envolvidos.

Enquanto no Brasil a gestão territorial visa a articular a política de ordenamento territorial nacional com a política de desenvolvimento regional, em Portugal a política de ordenamento territorial é produzida juntamente com o planejamento do desenvolvimento regional como uma política pública. De acordo com Feenberg (2007, p. 19), a política pública pode ser entendida como um meio ou um conjunto de meios; assim, "[...] esses meios permitem que o indivíduo coordene seu comportamento enquanto persegue êxito individual, numa atitude instrumental diante do mundo". Já para Kauchakje (2007), políticas públicas são formas de planejamento governamental que têm o objetivo de coordenar os meios e recursos do Estado, e também do setor privado para a realização de ações relevantes e politicamente determinadas.

Em outras palavras, políticas públicas implicam atividade de organização do poder e são instrumentos de ação do governo com as seguintes características: implicam a fixação de metas, diretrizes ou planos governamentais; distribuem bens públicos; transferem bens desmercadorizados; estão voltados para o interesse público, pautado nos embates entre interesses sociais contraditórios e são base de legitimação do Estado. Toda política pública é uma forma de intervenção na vida social, estruturada a partir de processos da articulação de consenso e de embate entre agentes sociais com interesses diversos decorrentes de suas posições diferenciadas nas relações econômicas, políticas, culturais e sociais. (KAUCHAKJE, 2007, p. 61-68). 
Ferrão (2011) defende a ideia de que o ordenamento do território como política pública deve ter como base uma visão estratégica colaborativa-competitiva, possibilitando a participação de instituições, indivíduos e comunidades, atingindo o que ele denomina de modos de aprendizagem. Nesse aspecto, afirma que os processos de aprendizagem e, por essa via, de construção inteligente de políticas (intelligent policy-making) ocupam, pois, uma posição central nas sociedades contemporâneas.

A análise anterior, centrada na identificação e breve caracterização das pressões comuns, ou seja, das potenciais fontes externas de mudança, permite entender a natureza e as principais causas dos processos de convergência de culturas e sistemas nacionais de ordenamento do território. Ela deverá agora ser complementada por uma análise dos modos de aprendizagem associados, ou associáveis, às diferentes dinâmicas de mudança convergentes. (FERRÃO, 2011, p. 94).

Ainda de acordo com Ferrão (2011), para entender os sistemas de ordenamento de território é preciso entender também as culturas de ordenamento do território que são entendidas como valores e atitudes compartilhados pela comunidade científica, técnica, política, instituições (públicas e privadas) e os cidadãos, acompanhando uma visão mais moderna de ordenamento do território que, na língua inglesa, é reconhecida como spatial planning.

Os sistemas de ordenamento do território refletem inevitavelmente as condições políticas, institucionais e societais prevalecentes ao longo dos tempos nos países em que se desenvolveram. Assim sendo, a diversidade existente de sistemas de ordenamento de território deve ser entendida à luz dos contextos particulares - nacionais e, por vezes, regionais - em que foram concebidos e aplicados. (FERRÃO, 2011, p. 34).

Por fim, Ferrão (2011) faz uma reflexão interessante sobre ordenamento do território como política pública, 
destacando a necessidade de mudança nas políticas de ordenamento do território em Portugal, considerando os papéis das comunidades profissionais, dos representantes políticos e dos cidadãos na construção de territórios socialmente mais justos e que presem pela qualidade de vida de todos.

Considerando-se o fato de que as políticas públicas tendem a intervir no desenvolvimento econômico e nos problemas sociais, torna-se, portanto, importante ressaltar que elas se defrontam com a necessidade de expandir as relações com o poder público para poder potencializar o acesso aos direitos sociais. Exemplo disso é a política de mediação, que objetiva garantir ao indivíduo e à sociedade o acesso ao poder judiciário.

\section{Território, mediação e conciliação}

No que se refere a território, mediação e conciliação, ressalta-se que, em 2015, já eram adotados meios alternativos, entre eles a mediação, como forma de resolver as disputas ocorridas, ainda que, de modo concreto e explícito, não existissem normas regulamentadoras da mediação no Brasil (CACHAPUZ, 2003). Da mesma forma, é importante destacar que a mediação é uma prática antiga porque ela é inerente à natureza humana (CALMON, 2007).

Assim sendo, a prática de mediação como uma forma de resolução de conflitos é utilizada desde a antiguidade. "Começando pelo diálogo até a guerra, são incontestáveis e informais os métodos utilizados pela humanidade para pôr fim aos seus conflitos. Os tribunais sempre foram a última opção" (SERPA, 1999, p. 67). Em Roma, havia a figura do árbitro ou mediador, pois o direito "[...] previa o procedimento in iure e o in iudicio que significam na presença do juiz, o primeiro, e do mediador ou árbitro, o segundo" (CACHAPUZ, 2003, p. 34).

De sua parte, Caser e Vasconcelos (2013) afirmam que a mediação é um processo estruturado e realizado a fim de prevenir conflitos entre os atores participantes de um dado processo, em que duas ou mais partes (stakeholders) são 
mediadas por um ou mais (mediadores), que atuam de forma neutra para ajudá-los a manter um diálogo produtivo e não vinculativo. Esse diálogo vai permitir que as partes, de forma autônoma, cheguem a uma solução consensual para melhorar a sua situação ou para resolver o seu litígio.

Portanto, a mediação prima pelo consenso de colaboração e construção ou visa à gestão de situações de conflito sem que haja a necessidade de se recorrer a um tribunal (MOORE, 2003).

A partir da confiança e da comunicação que são possibilitadas, na mediação, novos projetos conjuntos podem surgir e a procura pelo consenso em situações de crise passa a ser comum. O diálogo inclusivo e o reconhecimento das diferenças são basilares para a construção de consenso, sendo essa indicada para processos que envolvam muitos grupos. Assim, a possibilidade de associação da temática medição com território pode ser percebida quando tais temas são analisados sob a perspectiva da busca pela "paz social", considerada harmonia com a sociedade, onde são mantidas boas relações entre comunidades de indivíduos.

Segundo Caser e Vasconcelos (2013), devido à crescente complexidade e à dinâmica transfronteiriça internacional, o ordenamento do território torna-se inseguro e vulnerável devido aos conflitos. Por isso, a mediação pode ser configurada como um processo participativo interativo para tomada de decisão colaborativa, liderada por profissionais externos, sem uma participação no resultado.

\section{Mediações e conciliações como política pública}

Conforme a Resolução no 125 do CNJ (BRASIL, 2010), a partir da Lei no 13.140 , de 2015, a mediação foi instituída enquanto política pública de tratamento consensual de conflitos, sendo seu local de atuação a sociedade que possui como base de operações o pluralismo de valores, a presença de sistemas de vida diversos e alternativos, na medida em que "[...] sua finalidade consiste em reabrir os canais de 
comunicação interrompidos e reconstruir laços sociais destruídos” (SPENGLER, 2010, p. 312).

Assim, a mediação é um instrumento de tratamento de conflito que tem como objetivo facilitar o diálogo dos envolvidos, mas sem regras precisas. É vista, ainda, como uma forma de autocomposição de conflitos. A palavra mediação remete à definição de meio e de equilíbrio a um terceiro elemento que se encontra entre as duas partes. A diferença substancial entre mediação e conciliação é que a conciliação ocorre quando um terceiro atua como intermediário entre as partes tentando facilitar o diálogo, a fim de que as partes cheguem a um acordo, já a mediação ocorre quando um terceiro se coloca entre as partes e tenta conduzi-los a um acordo, à autocomposição.

Portanto, a mediação e a conciliação trazem consigo, além de um novo caminho, a possibilidade de mudança de mentalidade, que proporciona o desenvolvimento de uma cultura do diálogo, a qual viabiliza que, em um conflito, as próprias partes envolvidas assumam responsabilidades frente à solução de suas controvérsias.

Quando nos referimos a mediações e conciliações como política pública, é importante reiterar que as políticas públicas estudadas do ponto de vista da política servem para analisar o governo à luz de grandes questões públicas que refletem na vida dos cidadãos, imprimindo questões como "quem ganha o quê?"; "por quê?"; e "que diferença faz?" (SOUZA, 2006).

Considera-se, dessa forma, que a área de políticas públicas conciliou o conhecimento científico/acadêmico com a produção empírica dos governos. Percebe-se que Simon (1957) inseriu o conceito de "racionalidade limitada dos decisores públicos" (policy makers); Lindblom (1959) discutiu a ênfase no racionalismo de Laswell e Simon, propondo a incorporação de outras variáveis para formular e analisar as Políticas Públicas; e Eastone (1965) contribuiu ao definir a Políticas Públicas como um sistema formatado por uma relação entre a formulação, os resultados e o ambiente. (SOUZA, 2006) 
Em decorrência, o conceito de políticas públicas vem ganhando relevância na agenda de agentes políticos responsáveis por tomadas de decisões. Não existe um único conceito sobre o tema, visto que diferentes autores apresentam várias compreensões:

Mead (1995) a define como um campo dentro do estudo da política que analisa o governo à luz de grandes questões públicas e Lynn (1980), como um conjunto de ações do governo que irão produzir efeitos específicos. Peters (1986) segue o mesmo veio: política pública é a soma das atividades dos governos, que agem diretamente ou através de delegação, e que influenciam a vida dos cidadãos. Dye (1984) sintetiza a definição de política pública como "o que o governo escolhe fazer ou não fazer”. A definição mais conhecida continua sendo a de Laswell, ou seja, decisões e análises sobre política pública implicam responder às seguintes questões: quem ganha o quê, por que e que diferença faz. (SOUZA, 2006, p. 24).

Ainda sobre esse assunto, Souza (2006, p. 69) garante que "[...] a formulação de políticas públicas constitui-se no estágio em que os governos democráticos traduzem seus propósitos e plataformas eleitorais em programas e ações que produzirão resultados ou mudanças no mundo real".

Por sua vez, Secchi (2010,p.9) salienta que "[...] a política pública é um conceito abstrato que se materializa por meio de instrumentos variados". O referido autor ressalta, ainda, que um estudo de política pública não prescinde do estudo de um problema que seja entendido como coletivamente relevante (SECCHI, 2010).

No que se refere ao problema público, Secchi (2010, p. 7-8) o define como a diferença entre a situação ideal possível para a realidade pública. Destaca, também, que “[...] um problema só se torna público quando os atores políticos intersubjetivamente o consideram problema (situação inadequada) e público (relevante para a coletividade)".

Dessa forma, considerando-se o fato de que a mediação de conflitos tem como principal desafio encontrar 
mecanismos que possibilitem uma convivência pacífica, as políticas públicas são vistas como o conjunto de ações políticas voltadas ao atendimento de demandas sociais, associadas ao desenvolvimento. Assim sendo, as políticas públicas demonstram a execução do poder político, o que envolve a distribuição e a redistribuição de poder, os processos de decisão e seus conflitos, além da repartição de custos e recursos para oferta de bens e serviços públicos (TEIXEIRA, 2002).

\section{Considerações finais}

No presente trabalho, procurou-se evidenciar a necessidade da implantação não apenas de um planejamento mas também de métodos para resolução de conflitos, como conciliações e mediações para promover melhores decisões. Para melhor esclarecimento sobre o assunto, foram propostas várias discussões e levantadas diversas questões que percorrem os temas ordenamento territorial, desenvolvimento regional, conciliação, mediação e políticas públicas. Nesse contexto, concorda-se com Caser e Vasconcelos (2013), visto que a medição contribui para que se avaliem diferentes interesses e necessidades envolvidos em um conflito, evitando-se, dessa forma, que sejam atendidas necessidades individuais em detrimento de necessidades e interesses coletivos, embora durante a fase de exploração de interesses e necessidades, descubram-se interesses comuns. Assim, é estabelecido um processo dinâmico de discussão e de reflexão que tenta compreender a situação em sua totalidade.

Conforme ressaltado por Caser e Vasconcelos (2013), a mediação não serve apenas em situações de conflito em que o processo tradicional fracassou ou quando se prevê uma forte resistência da sociedade civil. $\mathrm{Na}$ realidade, a mediação implica capacitar os "grupos mais fracos", e isso não significa que os planejadores terão menos poder, mas, sim, que tais grupos poderão expressar suas ideias.

O Brasil é um país de grandes diversidades e, sob o aspecto social, é um complexo de diferentes grupos humanos, 
com territorialidades próprias, marcado por diversos interesses que, por muitas vezes, têm a necessidade de conciliar-se entre si. Essa diferenciação existente em diversas regiões do país e em vários segmentos pode ser vista como uma potencialidade e não como um problema, pois é preciso considerar o grande potencial brasileiro e sua diversidade regional. Nesse contexto, emerge uma essencial visão estratégica do território nacional para a articulação política.

Dessa forma, constatou-se, por meio do presente estudo, que o processo de mediação e de conciliação devolve aos indivíduos, ou seja, aos mediandos (autor e réu), a chance de resolver um conflito com a ajuda de um terceiro neutro e imparcial, que seria o mediador. Além disso, ficou demonstrada a satisfação dos mediandos em poder realizar um acordo sem delegar a outra pessoa, como um Juiz, a tomada de decisões, pois a mediação é um instrumento que permite a participação ativa dos indivíduos na busca de uma solução para os seus conflitos.

Portanto, a conciliação dos objetivos do desenvolvimento com os das potencialidades e das diversidades requer uma reformulação dos modos das gestões e decisões públicas, pois não basta estabelecer um planejamento e ordenamento territorial, também é preciso haver uma integração das ações e, com isso, a efetivação das mediações e conciliações.

Por fim, conforme referido por Brandão (2012), somente haverá outro mundo possível, quando existir outro ser humano possível, mas este somente existirá quando soubermos criar outra educação possível ou, ainda, pode ser estimulado a partir da mediação na medida em que esta possibilita a resolução de conflitos de forma pacífica, considerando-se os interesses e as necessidades dos envolvidos.

\section{Referências}

BRASIL. Resolução no 125, de 29 de novembro de 2010. Dispõe sobre a Política Judiciária Nacional de tratamento adequado dos conflitos de interesses no âmbito do Poder Judiciário e dá outras providências. Disponível em: <http://www.cnj.jus.br/files/atos_ 
administrativos/resoluo-n125-29-11-2010-presidncia.pdf>. Acesso em: 15 mai. 2016.

BRANDÃO, Carlos Rodrigues. Alguns passos pelos caminhos de uma outra educação. 2012. Disponível em: <http:/www.fbes.org.br/index. php?option=com_content\&task=view\&id=6708\&Itemid=62 >. Acesso em: 5 ago. 2016.

CACHAPUZ, Rozane da Rosa. Mediação nos conflitos \& Direito de Família. Curitiba: Juruá, 2003.

CASER, U.; VASCONCELOS, L. Mediation - How to promote better decision in Satial Planning- 1 st International MeetingGeography \& Politics, Policies and Planning. Porto: Publicaçoes Electronicas, 2013. p. 157-166.

CALMON, Petrônio. Fundamentos da mediação e da conciliação. Rio de Janeiro: Forense, 2007.

ETGES, Virgínia Elisabeta. Desenvolvimento regional sustentável: o território como paradigma. Redes, Santa Cruz do Sul, v. 10, n. 3, p. 47-55, set./dez. 2005.

FEENBERG, Andrew. Marcuse ou Habermas: Duas Críticas da Tecnologia. Tradução de Newton Ramos de Oliveira. 2007. Disponível em: <http://www.sfu.ca/ andrewf/marhabportu.htm>. Acesso em: 10 ago. 2016.

FERRÃO, João. O ordenamento do território como política pública. Lisboa: Fundação Calouste Gulbenkian, 2011.

KAUCHAKJE, Samira. Gestão Pública de Serviços Sociais. Curitiba: IBPEX, 2007.

LASWELL, Harald D. Politics: Who Gets What, When, How. Cleveland: Meridian Books, 1936.

MOORE, Christoper W. O processo de mediação: estratégias práticas para a resolução de conflitos. Tradução de Magda frança Lopes. Porto Alegre: Arted, 2003.

SANTOS, Milton. Por uma economia política da cidade. São Paulo: Hucitec, 1994.

SECCHI, Leonardo. Políticas Públicas: conceitos, esquemas de análise, casos práticos. São Paulo: Cengage Learning, 2010.

SERPA, Maria Nazareth. Teoria e prática da mediação de conflitos. Rio de Janeiro: Lúmen Iuris, 1999. 
SIMON, Herbert A. Comportamento Administrativo. Rio de Janeiro: USAID, 1957.

SORRENTINO, Marcos. Educação ambiental como política pública. Ministério do Meio Ambiente, Educação e Pesquisa, São Paulo, v. 31, n. 2, p. 285-299, maio/ago. 2005.

SOUZA, Celina. Políticas Públicas: Uma revisão da literatura. Sociologias, Porto Alegre, ano 8, n. 16, p. 20-44. jul./dez. 2006.

SPENGLER, Fabiana Marion (Org.). Mediação enquanto política pública: a teoria, a prática e o projeto de lei. Santa Cruz do Sul: EDUNISC, 2010.

TEIXEIRA, Elenaldo Celso. O Papel das Políticas Públicas no Desenvolvimento Local e na Transformação da Realidade. 2002. Disponível em: <http://www.dhnet.org.br/dados/cursos/aatr2/a pdf/03_aatr_pp_papel.pdf $>$.Acesso em: 6 ago. 2016.

Submetido em: 19/09/2016

Aprovado em: 12/07/2017 


\title{
REGIONAL PLANNING AND THE RESOLUTION OF CONFLICTS INTHE TERRITORY FROMTHE PUBLIC POLICY MEDIATION
}

\begin{abstract}
In this article, an analysis of the reflections and the conceptual elements related to the subject of territorial planning and the resolution of conflicts through mediation is carried out. As regards land use planning, some authors' works, such as Joao Ferrão and Ursula Caser, are used as references for understanding the theme from an interdisciplinary perspective. We sought to highlight the need to implement not only planning, but also methods that contribute to conflict resolution, such as reconciliation and mediation. In this context, some reflections related to territorial planning, regional development, conciliation, mediation and public policies are carried out. The methodology is based on a bibliographical research. The main conclusions point out that Brazil, being a country of great diversity and, under the social aspect, is a complex of different human groups, with its own territorialities, marked by different interests that, for many times, need to be reconciled each other. In addition, it was found that, after the completion of the mediation process is something more than simply a solution to the conflict, because in reality and in some cases also means the resumption of relations which were strained due to judicial stalemate. In the aspect of territorizalização, mediation is a process of social development, in that it seeks to assist the local population in the face of situations that cause wear, whether emotional, financial or social.
\end{abstract}

Keywords: Public policy. Territory. Conciliation. Mediation. 